\title{
O uso do marketing cultural como instrumento de relações públicas institucionais
}

\author{
The use of cultural marketing \\ as an instrument of \\ institutional public relations
}

El uso del marketing cultural como instrumento de relaciones públicas institucionales

Simone Alves de Carvalho

- Mestre em Ciências da Comunicação na Escola de Comunicações e Artes da Universidade de São Paulo (ECA-USP)

- MBA em Gestão Empresarial pela Fundação Getúlio Vargas (IBE-FGV)

- Especialista em Propaganda e Marketing pela Universidade de São Judas Tadeu (USJT)

- Bacharel em Comunicação Social, com habilitação em Relações Públicas, pela ECA-USP

•simonecarvalho@usp.br; sissicarvalho@uol.com.br 
O marketing cultural está diretamente relacionado com as relações públicas institucionais por terem, ambos, objetivos comuns: melhoria da imagem, busca de relacionamentos diferenciados com seus públicos e desenvolvimento da sociedade. Para tanto, os projetos devem ser dirigidos, específicos e relacionados com o universo da marca.

PALAVRAS-CHAVE: MARKETING CULTURAL • RELAÇÕES PÚBLICAS INSTITUCIONAIS • PROJETOS CULTURAIS

\section{Abstract}

Cultural marketing is directly related to institutional public relations, as both activities have common goals: enhancement of image, the search for differentiated relationship with their publics and development of the society. Thus, the projects should be targeted, specific and related to the universe of the brand.

KEYWORDS: CULTURAL MARKETING • INSTITUTIONAL PUBLIC RELATIONS • CULTURAL PROJECTS

\section{Resumen}

El marketing cultural está directamente relacionado con las relaciones públicas institucionales, ya que ambos tienen objetivos comunes: la mejora de la imagen, la búsqueda de relaciones diferenciadas con sus públicos y el desarrollo de la sociedad. Para ello, los proyectos deben ser dirigidos, específicos y guardar relación con el universo de la marca.

PALABRAS CLAVE: MARKETING CULTURAL・RELACIONES PÚBLICAS INSTITUCIONALES • PROYECTOS CULTURALES 
Com o acirramento da concorrência direta e indireta, as empresas buscam cada vez mais se diferenciar no mercado para conquistar consumidores e satisfazer seus diversos públicos de interesse. E uma das maneiras possíveis de se diferenciar é o uso do marketing cultural, ou seja, do patrocínio de atividades culturais ligadas ao nome da empresa. Não obstante, em nossa sociedade da informação, muitos são os fatores que impulsionam o marketing cultural: existe maior disponibilidade de tempo para o lazer; a internet facilitou o acesso e a interatividade com a comunicação e a informação; a sociedade vem se tornando mais ativa e crítica; e a propaganda tradicional enfrenta limitações para atingir o público-alvo.

As empresas fazem uso do chamado marketing cultural para alavancar sua imagem institucional com seus públicos de interesse, o que claramente é uma atividade de relações públicas. Entretanto, muitas organizações nomeiam como "departamento de marketing" aqueles responsáveis pela comunicação, tanto interna/ administrativa quanto institucional e mercadológica propriamente dita, de maneira que a atividade de marketing cultural nem sempre está diretamente relacionada com as relações públicas. Apesar de existir discordância sobre a nomenclatura marketing cultural, ela é corrente tanto no meio acadêmico como no profissional, motivo pelo qual a utilizaremos para designar as atividades de patrocínio sobre ações culturais e artísticas. A educação e a cultura têm o poder de transformar socialmente um país, criando uma sociedade analítica e mais justa, em que a informação é devidamente valorizada.

Neste artigo, pretendemos mostrar que marketing cultural deve ser encarado como uma atividade que visa à manutenção de relacionamentos institucionais, buscando a melhoria de imagem e a divulgação da empresa como culturalmente responsável. Iniciaremos com um breve olhar histórico, conceituaremos marketing cultural e relações públicas institucionais e finalizaremos com a junção dos dois temas, apontando ainda que, quando os mecanismos de renúncia fiscal são utilizados indevidamente, o marketing cultural pode obter um resultado negativo, que pode arranhar a imagem e a reputação da organização.

\section{ANTECEDENTES HISTÓRICOS}

A cultura é "um conjunto de características espirituais, materiais, intelectuais e afetivas distintas, que caracterizam uma sociedade [...] [e abarca] artes, letras, os modos de vida, os sistemas de valores, as tradições e as crenças" (BRANT, 2003 , p. 3), ou seja, a vida em sociedade tal como a conhecemos é fruto de uma cultura secular, que se transforma ininterrupta e constantemente. Brant (2003, p. 4) ainda afirma que "a falta de visão crítica e de referências culturais que consolidam a identidade de um povo faz com que ele se torne mais suscetível aos valores descartáveis da sociedade de consumo", reafirmando a necessidade social da cultura. Ribemboim (2003, p. 125) define sucintamente que 
"a cultura e a arte são infinitamente amplas, trafegam do popular ao erudito, do adulto ao infantil, do intricado ao mais simples significado", ou seja, a cultura consegue atingir a todas as pessoas, independentemente de classe social, credo, gênero, cor e outras fontes de preconceito social, unindo as pessoas no conhecimento aprofundado da sociedade em que vivemos e buscando meios para o desenvolvimento.

As origens do marketing cultural remontam ao mecenato, que deve seu nome a

Gaius Maecenas, amigo pessoal do omperador Caio Augusto, que exerceu funções administrativas no império romano, entre 30 a. C. e $10 \mathrm{~d}$. C. [...] foi um grande articulador das ligações entre o Estado romano e o mundo das artes (REIS, 2003, p. 6).

Como podemos observar, o poder público se responsabilizava pela cultura naquela época, pois "Mecenas entende que o poder necessita se fazer cercar da criação artística e do pensamento, na busca de sua legitimidade, [já que] os eruditos emprestam credibilidade" (ALMEIDA, 1993, p. 17). Já na Europa renascentista, a figura do mecenas atinge seu auge quando "as cortes europeias empenham largas somas no financiamento a cultura” (ALMEIDA, 1993, p. 18) e também ocorre uma transformação social: os banqueiros e comerciantes necessitam de prestígio para se inserir na sociedade. Destaca-se na época o mecenato de origem católica, que utilizava a arte para transmitir mensagens religiosas (REIS, 2003).

Segundo Almeida (1993), a Revolução Industrial vai acelerar a separação entre poder público e mecenato, pois a sociedade será novamente transformada e o significado de público e privado será alterado. Até a Primeira Guerra Mundial, o mecenato nos Estados Unidos é praticado por grandes industriais, muitos deles com problemas de imagem, causados pela maneira como conduziam seus negócios. Posteriormente, a cobrança dos impostos devidos pelas pessoas será modificada de maneira a se deduzir do imposto devido o valor gasto com investimentos culturais, o que impulsiona a participação das empresas nas atividades de patrocínio (sponsoring). A mudança do nome é sintomática da mudança de significado que a subvenção às artes sofreu ao longo do tempo. Nessa época a profissão de relações públicas começa a se consolidar politicamente com a atuação de profissionais como Ivy Lee e Edward Bernays (KUNSCH, W., 2009).

No Brasil, até o Estado Novo, existiu vagamente o mecenato com essa nomenclatura, por meio de atitudes de algumas pessoas isoladas, como Yolanda Penteado e Assis Chateaubriand. A partir dessa época, o então presidente Getúlio Vargas percebe a convergência entre poder e arte e cria "uma política cultural quase oficial, plantando as bases do nacionalismo nesta área" (ALMEIDA, 2003, p. 25), que envolve artistas brasileiros de renome e aproxima a cultura do poder. No entanto, com o período de ditadura militar a 
partir da década de 1960, a atitude governamental perante as artes muda, especialmente com a criação de órgãos para fomentar a produção cultural considerada apropriada pelo regime.

Com a redemocratização, são criados diferentes mecanismos de incentivos fiscais às atividades culturais. Em 1986 foi instituída a Lei Sarney, que "previa benefícios fiscais para pessoas físicas ou jurídicas que efetuassem investimentos, patrocínios ou doações em projetos de natureza cultural” (ALMEIDA, 1993, p. 51), revogada no início do governo Collor. Entretanto, os governos estaduais e municipais, nessa época, criaram mecanismos próprios de incentivo à cultura, utilizando percentuais de desconto sobre impostos de sua competência, tais como ICMS, ISS e IPTU. Em 1991 foi promulgada a Lei Rouanet, "de âmbito nacional, cujos efeitos e procedimentos se aplicam a qualquer projeto executado no país” (ALMEIDA, 1993, p. 53). A criação de leis específicas regulamentou o setor de produção cultural e transformou o antigo mecenato, feito de maneira espontânea e descompromissada, em uma atividade sistematizada e lucrativa. Com essa mudança, passamos às atividades de patrocínio e apoio.

Segundo Reis (2003, p. 12), “o patrocínio só floresceu realmente a partir da década de $70,[\ldots]$ pela mudança de orientação de foco no produto para foco no mercado". Mas a autora também aponta que muitas empresas brasileiras patrocinaram megaeventos com a finalidade única de divulgação, sem ter uma estratégia de comprometimento cultural, o que prejudica o verdadeiro significado do patrocínio, que deve ser uma estratégia de comunicação e apresentar retorno sobre o investimento.

Para Costa (2004, p. 19), patrocínio é "o pagamento em dinheiro, produtos ou serviços a uma organização ou evento (cultural, esportivo, de entretenimento ou sem fins lucrativos), tendo como contrapartida o acesso à exploração do potencial comercial dessa atividade”. Portanto, o patrocinador usufrui do projeto que está sendo patrocinado e pode utilizá-lo para fins institucionais. A empresa que decidir patrocinar uma atividade cultural também pode optar pela prática do patrocínio cruzado, por meio de apoio, com cotas de patrocínio diferenciadas; ou colaboração, por meio de permutas. Caso opte por essas modalidades, a empresa dividirá sua visibilidade com outras empresas envolvidas no projeto e deverá cuidar para que a imagem das outras empresas envolvidas não cause problemas para sua própria reputação. Segundo Sarkovas (2008),

as legislações de incentivos fiscais transferem mais de R\$ 1 bilhão por ano de dinheiro público para empresas decidirem onde aportá-lo. A maior parte canalizado pelas leis Rouanet e do Audiovisual, que permitem dedução direta e integral no imposto de renda a pagar.

Para o autor, temos no Brasil um sistema único que permite ao empresário decidir onde será investido o dinheiro público, proveniente da renúncia fiscal, mas ele considera esse sistema perdulário e injusto, com o que concordamos. 


\section{MARKETING CULTURAL}

Para Fischer (2002, p. 19), “o marketing cultural é um recurso utilizado com a finalidade de fixar a marca de uma empresa ou entidade por meio de diversas ações culturais, tais como a música, a arte, o esporte, a literatura, o cinema, o teatro". O marketing cultural comunica um produto ou serviço, bem como outras formas de atividades comunicacionais, mas ele se diferencia por trazer o produto para mais próximo do ambiente relacional do consumidor, ao inserir uma determinada marca ou produto em um grupo musical ou um filme do gosto desse consumidor. Para Almeida (1993, p. 31), a arte confere prestígio a qualquer ação mercadológica. Já Possendoro (2003, p. 134) afirma que o "marketing cultural é uma atividade genuinamente nacional, fruto da junção de alguns fatores sociais. O embrionário foi a carência social, [pois] o Estado não tem condições de atender a todas as demandas culturais da sociedade". Ele finaliza o pensamento afirmando que a empresa, a terceira ponta desse tripé, precisa que a cultura e a educação existam para sobreviver no mercado e ter colaboradores e consumidores bem informados. Por outro lado, ela também é dependente da sociedade para sobreviver, para vender seus produtos e serviços.

A atividade cultural se divide em produto cultural e evento cultural, ambos podendo ser patrocinados com finalidades institucionais. O produto cultural é um bem físico, tangível, durável, sendo exemplos livros de fotografia e filmes. Já o evento cultural é voltado a um grupo menor de pessoas, que está presente fisicamente ao evento. Ele é esporádico e único, como um show, ima peça de teatro e uma exposição. Evidentemente, um produto cultural pode fazer parte de um evento cultural. O que nos afeta aqui é a exposição da marca ao público e como ela será entendida.

Uma pesquisa realizada pelo Instituto Cultural Cidade Viva (ICCV, 2003), com noventa grandes empresas que investiam em marketing cultural, apontou que elas foram motivadas pelo fortalecimento da imagem institucional $(19,49 \%)$, seguindo-se a participação no desenvolvimento cultural local e nacional $(17,81 \%)$ e a responsabilidade social $(16,95 \%)$. Outras respostas obtidas foram: fixação da marca $(9,32 \%)$, atingir o público-alvo da marca $(8,47 \%)$, associação a projetos de qualidade $(7,63 \%)$, retorno de mídia e divulgação $(6,78 \%)$ e uso do benefício fiscal $(5,08 \%)$.

O uso do benefício fiscal está relacionado com as leis de incentivo à cultura do país. As diferentes leis, nos âmbitos federal, estaduais e municipais, possuem mecanismos e valores diversos, mas a ideia geral é que a ação cultural seja aprovada previamente pelo órgão público respectivo; Após a aprovação, o produtor cultural passa a captar recursos e a empresa que se identifique com o projeto cultural oferece os recursos necessários para a consecução do projeto, desde que dentro da faixa percentual de renúncia fiscal prevista na lei. Após a execução do projeto, deve ser enviado ao órgão competente um relatório detalhado e acompanhado das notas fiscais referentes à realização da ação, ou seja, 
existe uma geração de novos impostos com a atividade cultural, de maneira que não ocorre perda para a sociedade. Além disso, as atividades provenientes do planejamento do marketing cultural movimentam a economia com geração de empregos, diretos e indiretos, e também de renda, por meio da venda de produtos e serviços relacionados ou não com a ação cultural.

Para Melo Neto (2000, p. 41) e Fischer (2002, p. 47), existem no Brasil alguns empecilhos ao marketing cultural, que são: pouca tradição de patrocínio cultural; desconhecimento das leis de incentivo fiscal; excesso de burocracia dos órgãos públicos de fomento à cultura; instabilidade financeira recente; baixa percepção dos benefícios existentes; falta de dados estatísticos sobre o investimento em cultura; pouco profissionalismo dos envolvidos; falta de contrapartida interessante para a divulgação da marca; projetos culturais inadequados ao tipo de produto ofertado pela empresa.

\section{RELAÇÕES PÚBLICAS INSTITUCIONAIS}

O profissional de relações públicas é responsável por planejar e executar atividades comunicacionais que estabeleçam e mantenham a compreensão mútua entre organização e seus públicos de interesse. Para tal fim, ele possui uma vasta gama de instrumentos que podem ser utilizados para a consecução da comunicação integrada dentro das organizações.

A comunicação integrada é composta, de acordo com Margarida Kunsch, do seguinte tripé: comunicação interna/administrativa, ou seja, os fluxos, as redes e os sistemas de comunicação dentro da organização, direcionada para seus colaboradores; comunicação mercadológica, que busca a divulgação dos produtos por meio da mídia de massa; e a comunicação institucional, "responsável direta [...] pela construção e formatação de uma imagem e identidade corporativas fortes e positivas de uma organização” (KUNSCH, M., 2003, p. 164).

Além do marketing cultural, podem ser utilizadas para fins institucionais outras atividades, como marketing social e marketing esportivo, que se assemelham, porém possuem objetivos e públicos diferentes. Dependendo da ação cultural realizada, ela também poderá ser considerada social ou até mesmo ambiental, se ela envolver, por exemplo, campanhas educativas sobre cidadania, saúde, reciclagem, entre outras possibilidades.

Relações públicas têm como referência a opinião pública, a ética e os valores de uma organização, todos relacionados com a comunicação institucional. Já a comunicação mercadológica vai se pautar pela distribuição e pela relação oferta/demanda. Ao unirmos os dois conceitos, teremos uma ferramenta que atinge os públicos de interesse, relacionado com algo que ele está disposto a utilizar ao mesmo tempo em que a marca de uma empresa é divulgada em uma situação de consumo diferenciada. 


\section{MARKETING CULTURAL E RELAÇÕES PÚBLICAS INSTITUCIONAIS}

Para Almeida (1993, p. 30), "o mecenas moderno possui objetivos bastante definidos: a inserção em determinado contexto social, satisfação de vaidades, a busca da posteridade ou o benefício fiscal”. Devemos também refletir sobre os itens que avaliam o sucesso ou não de um patrocínio cultural, como a geração de divulgação espontânea pelos meios impressos, eletrônicos e digitais, a melhoria da imagem da marca e a percepção do patrocínio por parte do público atingido.

Conforme afirma Farias (2007, p. 415),

o patrocínio é uma estratégia da organização - diluída em seu planejamento estratégico maior - que propõe estimular ações sociais, culturais, artísticas ou esportivas principalmente por meio de suporte financeiro, visando à obtenção de um retorno financeiro-comercial e/ou de imagem para a marca, para o produto ou para a organização.

Para que a atividade de patrocínio do marketing cultural seja representativa das relações públicas institucionais, a empresa deve possuir uma comunicação direta com o público-alvo, respeitando sua segmentação e identidade; se tornar referência como boa empresa para se trabalhar, pois a imagem só se consolida a partir de uma identidade coerente; manter relações com a comunidade, uma vez que a responsabilidade social e a sustentabilidade são valores intrínsecos ao século XXI; e trabalhar em prol da marca, buscando a integração das atividades comunicacionais, que, nas palavras de Margarida Kunsch (2003, p. 150), se caracteriza como sendo

a convergência de todas as atividades, com base numa política global, claramente definida, e nos objetivos gerais da organização, [possibilitando] ações estratégicas e táticas de comunicação mais pensadas e trabalhadas com vistas à eficácia.

O marketing cultural pode ser utilizado para segmentar o público-alvo de determinado produto, por meio da seleção da atividade artística patrocinada, e a partir desse recorte a comunicação institucional deve ser dirigida para esse público, maximizando seu resultado. Muylaert (1993, p. 30) afirma que o público deve ter a certeza da "impossibilidade da realização [do evento] sem o patrocinador, valorizando sua presença” para garantir o retorno institucional para a organização patrocinadora.

É importante que exista uma relação de conformidade entre a ação cultural realizada e a marca patrocinadora, sua identidade, sua imagem e seu posicionamento, para que o consumidor perceba a comunicação que está sendo realizada. O planejamento e a execução do evento cultural devem ser altamente competentes, para que não ocorra nenhuma situação que desabone a marca. 
A atividade cultural colabora com as relações públicas institucionais à medida que agrega vários de seus públicos de interesse, como os colaboradores, que podem ter acesso ao projeto cultural patrocinado; os acionistas, que recebem material diferenciado; a comunidade, por meio da geração de emprego e de renda, além do acesso à arte e cultura; a mídia, pois a empresa é divulgada em mídia diferenciada (cadernos de cultura e lazer), entre outros benefícios e públicos.

\section{A INDÚSTRIA DO MARKETING CULTURAL}

Ao nos debruçarmos sobre um tema qualquer para pesquisá-lo, nos deparamos também com algumas atrocidades ocorridas no mercado, que mancham a imagem das organizações e dos profissionais envolvidos. Embora haja um consenso positivo sobre o que foi dito anteriormente neste nosso artigo, encontramos situações em que a falta de ética fala mais alto.

O aumento das atividades relacionadas ao marketing cultural que ocorreu no Brasil a partir do final da década de 1980 foi provocado pelo surgimento de leis de incentivo em todas as esferas governamentais. Para Brant (2003, p. 10), essas leis foram "criadas para se tornarem ponte estratégica entre o setor privado e a cultura, considerada uma área de alto interesse estratégico para o desenvolvimento social”, conforme apontamos no início deste artigo. Historicamente, surgiu a Lei Sarney, extinta no governo Collor; a Lei Mendonça (em São Paulo), pioneira no modelo de dedução fiscal; a Lei Rouanet, "que reconhecia que o financiamento público à cultura não poderia ser regulado exclusivamente pelos interesses mercadológicos e/ou pessoais inerentes ao patrocínio e à doação privada" (SARKOVAS, 2000,); a Lei do Audiovisual, que "permite a uma empresa privada usar dinheiro público, sem nenhuma contrapartida”. Como podemos observar, as leis foram criadas para melhorar um aspecto social carente, mas os mecanismos permitem o mau uso do dinheiro público.

Embora as leis tenham sido criadas para angariar fundos para a produção cultural diversificada, como artes plásticas, música e cinema, entre outras com menor visibilidade, sua aplicação vem sofrendo com a falta de profissionalização do setor, pois, como afirma CUNHA (2003, p. 104),

há uma necessidade latente de investimentos na formação de profissionais da cultura, principalmente para que haja uma nova composição dos quadros de funcionários públicos, estruturados com profissionais de diversas áreas, às vezes sem conhecimentos suficientes sobre as especificidades do campo da cultura.

Brant (2003, p. 11) continua sua crítica ao modelo de marketing cultural que domina o mercado, ao mencionar que o governo aprova "inúmeros projetos sem nenhum critério", a empresa patrocinadora consegue reaver seu investimento, além da renúncia fiscal, e resta ao cidadão "comprar ingressos ou produtos a preços extorsivos". 


\section{CONSIDERAÇÕES FINAIS}

O marketing cultural, assim como a atividade de relações públicas, pode ser utilizado por empresas de qualquer porte, bastando que exista um planejamento adequado e condizente com a sua situação financeira. Se a empresa conhecer bem seu público-alvo, determinar objetivos e metas realistas e utilizar as redes sociais digitais como meio de divulgação, certamente terá um bom retorno institucional com o patrocínio de atividades culturais.

O profissional de relações públicas, por possuir uma formação humanística com características administrativas, se adequa ao perfil do profissional desejado pelo mercado para esse campo de atuação, pois ele conhece bem o tripé envolvido na atividade de marketing cultural: conhece os públicos de interesse; entende a empresa patrocinadora; e compreende a organização cultural. A opção pelo investimento em marketing cultural como atividade de relações públicas institucionais se mostra bastante acertada ao colocarmos em perspectiva todos os benefícios decorrentes: relacionamento dirigido com públicos de interesse; objetivos específicos de comunicação; adequação entre marca e projeto cultural patrocinado; e benefícios decorrentes do patrocínio.

Entretanto, aquele que desejar atuar nessa área deve levar em consideração que, apesar de estar em ligeira expansão desde a década de 1990, por conta das leis de incentivo fiscal em todas as esferas governamentais, a área carece de profissionais capacitados. Estes devem entender as estratégias de comunicação organizacional, relações públicas e marketing, além de dominar as áreas de arte, cultura, sociologia, antropologia e psicologia. São esses conhecimentos unificados que obterão resultados positivos, para a organização patrocinadora e para a comunidade que usufruirá de um espetáculo cultural relevante. A falta de profissionalismo é visível quando lemos sobre os desvios de verba ocorridos, ou mesmo quando o Ministério da Cultura (MinC) apresenta uma listagem de obras realizadas que nunca tivemos a oportunidade de prestigiar, pois não foram lançadas comercialmente. É importante lembrar também que, embora existam leis em todas as esferas do poder, nem todos os estados e municípios possuem suas leis próprias e, dentre aqueles que as criaram, nem todos publicam editais regularmente, contribuindo para o descompasso das atividades culturais no Brasil.

\section{REFERÊNCIAS BIBLIOGRÁFICAS}

ALMEIDA, Candido José Mendes de. A arte é capital: visão aplicada de marketing cultural. Rio de Janeiro: Rocco, 1993.

BRANT, Leonardo. Diversidade cultural e desenvolvimento social. In: BRANT, Leonardo (Org.). Políticas culturais. Vol. 1. Barueri, SP: Manole, 2003. p. 3-13.

COSTA, Ivan Freitas da. Marketing cultural: o patrocínio das atividades culturais como ferramenta de construção de marca. São Paulo: Atlas, 2004.

CUNHA, Maria Helena. Formação do profissional de cultura: desafios e perspectivas. In: BRANT, Leonardo (Org.). Políticas culturais. Vol. 1. Barueri, SP: Manole, 2003. p. 103-106. 
FARIAS, Luiz Alberto de. Patrocínio, apoio e mecenato: importância e estratégias de uso. In: PEREZ, Clotilde; BARBOSA, Ivan Santo (Org.). Hiperpublicidade: fundamentos e interfaces. São Paulo: Thomson Learning, 2007.

FISCHER, Micky. Marketing cultural: legislação, planejamento e exemplos práticos. São Paulo: Global, 2002.

ICCV - Instituto Cultural Cidade Viva. Perfil de empresas patrocinadoras. Rio de Janeiro: Record, 2003.

KUNSCH, Margarida M. Krohling. Planejamento de relações públicas na comunicação integrada. 4. ed. - rev. atual. e ampl. São Paulo: Summus, 2003.

KUNSCH, Waldemar Luiz. Gênese e desenvolvimento do campo profissional e acadêmico das relações públicas no Brasil. In: KUNSCH, Margarida M Krohling (Org.).. Relações públicas: história, teorias e estratégias nas organizações. São Paulo: Saraiva, 2009.

MELO NETO, Francisco Paulo de. Marketing de patrocínio. Rio de Janeiro: Sprint, 2000.

MUYLAERT, Roberto. Marketing cultural e comunicação dirigida. São Paulo: Globo, 1993.

POSSENDORO, Alexandre. Muito além do jornalismo cultural. In: BRANT, Leonardo (Org.). Políticas culturais. Vol. 1. Barueri, SP: Manole, 2003. p. 133-136.

REIS, Ana C. Fonseca. Marketing cultural e financiamento da cultura: teoria e prática em um estudo internacional comparado. São Paulo: Pioneira Thomson Learning, 2003.

RIBEMBOIM, Ricardo. Cultura e responsabilidade social. In: BRANT, Leonardo (Org.). Políticas culturais. Vol. 1. Barueri, SP: Manole, 2003. p. 125-127.

SARKOVAS, Yacoff. Patrocínio cultural e identidade de marca. 2008. Disponível em: <http://comatitude.com.br/2008/01/27/ patrocinio-cultural-e-identidade-de-marca/ $>$. Acesso em out. 2010.

SARKOVAS, Yacoff. 0 incentivo fiscal à cultura no Brasil. 2000. Disponível em: <http://comatitude.com.br/2000/04/01/0-incentivo-fiscal-a-cultura-no-brasil/>. Acesso em: out. 2010.

Recebido em: 15.06.2010 / Aceito em: 30.08.2010 